УДК 631.22.

Банга B.I., к.T.н.

Львівський національний аграрний університет

\title{
ЕКСПЕРИМЕНТАЛЬНІ ДОСЛІДЖЕННЯ СЕНСОРА КРУТНОГО МОМЕНТУ СИСТЕМИ ПРИВОДУ «ЕЛЕКТРОДВИГУН-ДИСКОВИЙ ДОЗАТОР»
}

У статті подано огляд і аналіз пристроїв для вимірювання крутного моменту приводу обертових елементів, конструктивну схему та загальний вигляд сенсора крутного моменту,

передбачено наявність засобів для вимірювання, реєстрачиї та передачі інформаиії електричними сигналами біжучих значень вихідної напруги тензодатчиків в динамічному режимі, відображення і зберігання інформаџії та контрольно-вимірювальні прилади.

Наведено блок схему, загальний вигляд експериментальної установки для дослідження потужності приводу «електродвигун-дисковий дозатор» сенсором крутного моменту, результати експериментальних досліджень з використанням теорії багатофакторного планованого експерименту, подано рівні варіювання факторів, матриџю плану експерименту.

Запропонована конструкиія сенсора крутного моменту системи приводу «електродвигун-дисковий дозатор дозволить спростити зняття інформачії з сенсора при його обертанні, підвищити точність вимірювання та передачі вимірювального сигналу до комп'ютера, спростити його виготовлення.

У результаті проведення планованого багатофакторного експерименту одержано рівняння регресії для визначення вихідної напруги сенсора крутного моменту від зміни зусилля крутного моменту елементів, що обертаються при різних конструктивних розмірах тензовимірювальної площини.

Ключові слова: сенсор крутного моменту, дисковий дозатор, експериментальна установка, планований експеримент, вихідна напруга, тензодатчик.

Постановка проблеми. Задача вимірювання зусиль, які передаються обертаючим валом, була поставлена більше двох століть тому і не втратила своєї актуальності і в даний час. Це пояснюється широким розвитком та різноманітністю типів двигунів і силових установок, специфічні умови роботи яких вимагають застосування різноманітних вимірювальних засобів [1].

Основною вимогою, що ставляться до сенсорів крутного моменту системи приводу «електродвигун-дисковий дозатор є підвищення точності вимірювання. Це вимагає наявності технологічного обладнання, яке б забезпечило належну точність вимірювання та швидкодію знімання інформації в динамічному режимі. Тому розробка та дослідження вимірювача сенсора крутного моменту є актуальним і перспективним.

Аналіз останніх досліджень і публікацій. Проведений нами аналіз літературних джерел [1-4] дозволяє зробити висновок, що відомі сенсори крутних моментів мають низку недоліків, а саме низьку точність вимірювання, складність виготовлення при запіканні датчиків та конструкції.

Низька точність вимірювання пояснюється тим, що відбувається зменшення чутливості системи вал-сенсор, та наявністю нелінійної характеристики крутного моменту при розміщенні сенсорів на валу.

Складність виготовлення сенсора крутного моменту при наклеюванні і запіканні сенсорів пояснюється тим, що вал необхідно вставляти в термічну камеру. Тому розробка пристроїв для вимірювання крутного моменту є актуальною.

Постановка завдання. Метою дослідження $є$ розробка сенсора крутного моменту та дослідження зміни вихідної напруги тензодатчиків від зміни зусилля крутного моменту елементів, що обертаються.

Виклад основного матеріалу. В основу винаходу поставлена задача створення такого сенсора крутного моменту, в якому нове виконання вимірювального елементу дозволить підвищити точність вимірювання, усунути складність виготовлення при наклеюванні і запіканні датчиків. Схема і загальний вигляд експериментальної установки для дослідження потужності приводу «електродвигун-дозатор» сенсором крутного моменту показані на рис. 1. 
a)
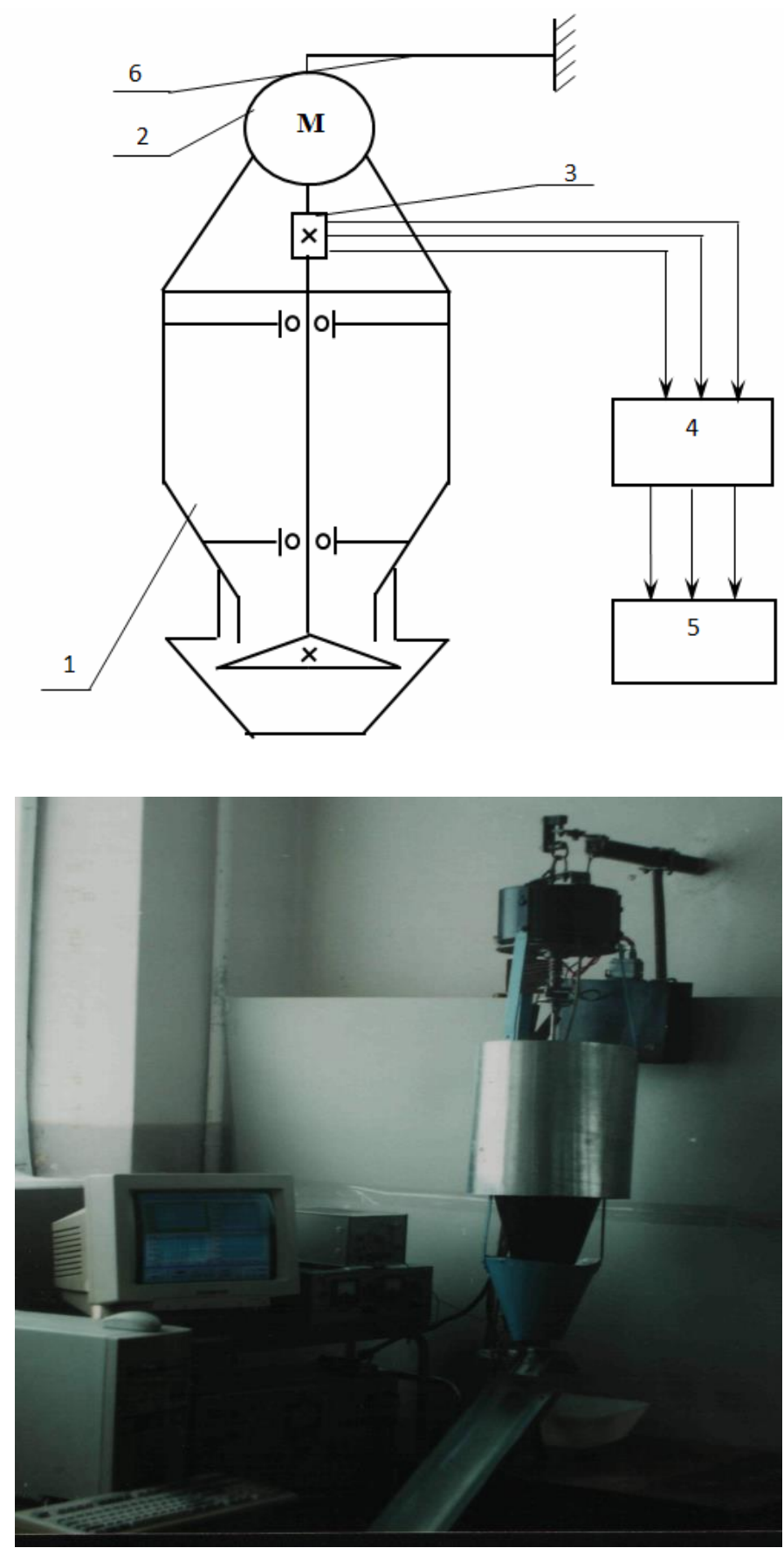

Рис. 1. Блок-схема (а) і загальний вигляд (б) експериментальної установки для дослідження потужності приводу «електродвигун-дисковий дозатор» сенсором крутного моменту:

1 - індивідуальний дисковий дозатор; 2 - електродвигун приводу дискового дозатора; 3 сенсор крутного моменту; 4 - тензопідсилювач 8АНЧ-7М; 5 - ПЕОМ; 6- кронштейн.

Для вимірювання потужності на привід дискового дозатора у верхній частині індивідуального дозатора 1 в розрив привідних валів на привід робочого органу та електродвигуна встановлено жорстко сенсор крутного крутного моменту 3 , який захищений деклараційним патентом України на винахід [5] . Схема і загальний вигляд показані на рис. 2.

Сенсор складається 3 привідного вала 1, до якого закріплені дві півмуфти 2, 3 жорстко закріпленими стояками 3 , на яких встановлена тензовимірювальна площина 4 з наклеєними на ній тензодатчиками 5 типу 2ПКП-5-100. На привідному валу 1 закріплена втулка 63 ізолюючого матеріалу, на якій встановлено жорстко кільця 7 зі щітками 8.

Сенсор працює таким чином. Привідний вал 1 приводить у рух півмуфти 2 зі стояками 3 , 
які діють на вимірювальну площину 4, внаслідок чого вона прогинається. Величина прогину, викликана зміною зусилля крутного моменту, фіксується тензодатчиками 5. Сигнал від 3 тензодатчиків 5 через кільця 7 та щітки 8 знімається на тензопідсилювач 9.
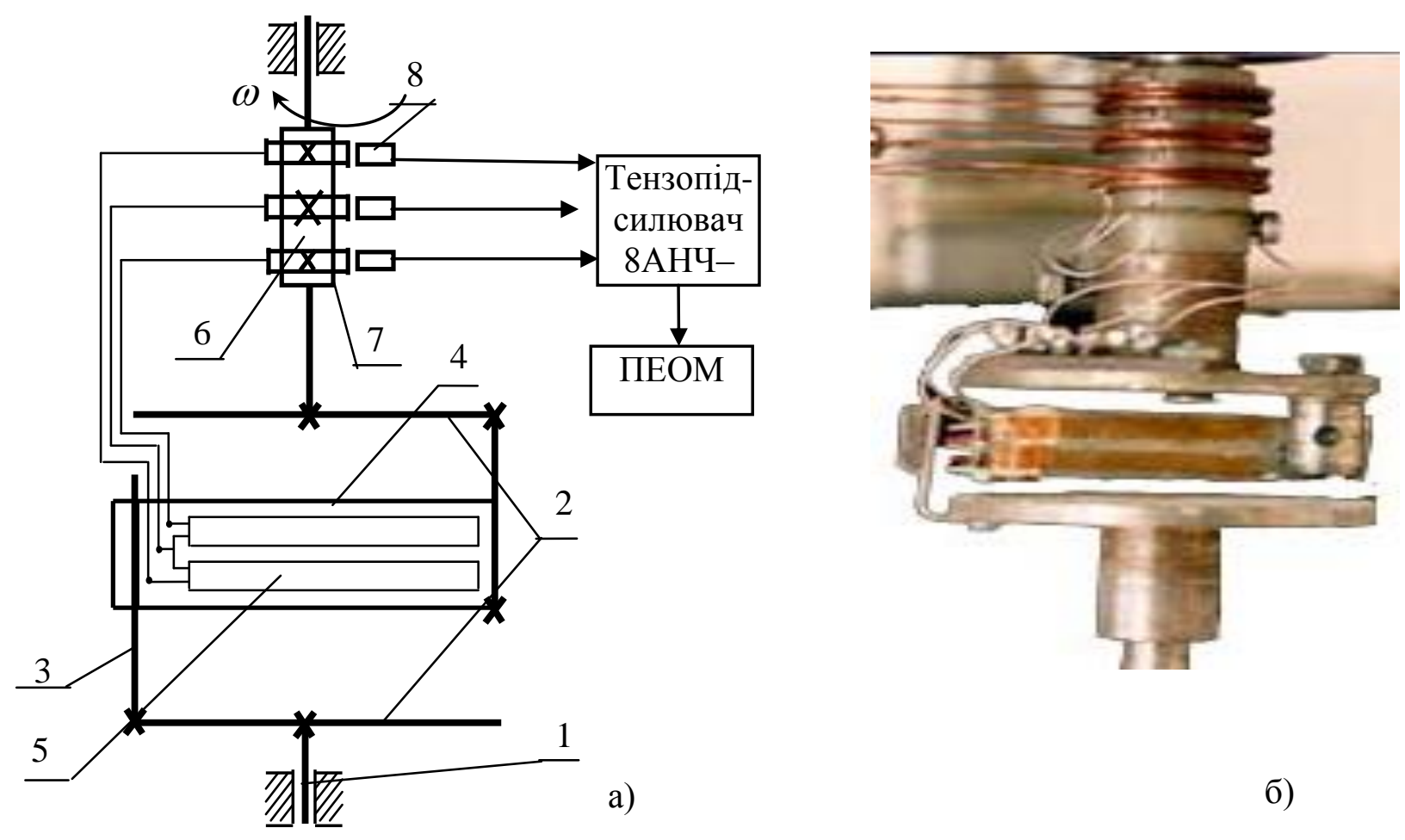

Рис. 2. Конструктивна схема (а) і загальний вигляд (б) сенсора крутного моменту: 1 - привідний вал; 2 - півмуфти; 3 - стояки; 4 - тензовимірювальна площина; 5 - тензодатчики; 6 - втулка; 7 - кільця; 8 - щітки.

Для обгрунтування конструктивно-технологічних розмірів тензовимірювальної площини проводився повний трифакторний планований експеримент на трьох рівнях типу $3^{\mathrm{K}}$, (к - число факторів) плану другого порядку Бокса-Бенкіна за відомою методикою [6-8]. Інтервали і рівні варіювання факторів наведені в табл. , а матриця плану у табл. 2.

За критерій оптимізації прийнято вихідну напругу тензодатчиків $U$.

Факторами, які впливають на вихідну напругу тензодатчиків $U$, були площа поперечного перерізу $S$, довжина тензовимірювального полотна $L$, крутний момент на валу $M$.

Таблиця 1.

Інтервали і рівні варіювання факторів

\begin{tabular}{|c|c|c|c|c|}
\hline $\begin{array}{c}\text { Рівень варіювання } \\
\text { факторів }\end{array}$ & $\begin{array}{c}\text { Кодовані } \\
\text { значення }\end{array}$ & $\begin{array}{c}\text { Площа поперечного } \\
\text { перерізу } S, \mathrm{~m}^{2}\end{array}$ & $\begin{array}{c}\text { Довжина } \\
\text { тензовимірю- } \\
\text { вального полотна } L, \\
\text { м }\end{array}$ & $\begin{array}{c}\text { Крутний } \\
\text { момент на валу } \\
M, \mathrm{H} \cdot \mathrm{M}\end{array}$ \\
\hline Верхній & + & 0,0875 & 0,165 & 0,42 \\
\hline Основний & 0 & 0,0625 & 0,125 & 0,2915 \\
\hline Нижній & - & 0,0375 & 0,085 & 0,163 \\
\hline $\begin{array}{c}\text { Інтервал } \\
\text { варіювання }\end{array}$ & $\varepsilon$ & 0,025 & 0,04 & 0,1285 \\
\hline
\end{tabular}


Таблиця 2.

Матриця плану експерименту

\begin{tabular}{|c|c|c|c|c|}
\hline \multirow{2}{*}{$№$ експерименту } & \multicolumn{3}{|c|}{ Варіювання факторами } & Критерій оптимізації \\
\cline { 2 - 5 } & $x_{1}$ & $x_{2}$ & $x_{3}$ & $U, \mathrm{~B}$ \\
\hline 1 & 1 & 1 & 0 & 3,9 \\
2 & -1 & -1 & 0 & 2,92 \\
3 & 1 & -1 & 0 & 3,8 \\
4 & -1 & 1 & 0 & 2,97 \\
5 & 0 & 1 & 1 & 4,67 \\
6 & 0 & -1 & -1 & 2,1 \\
7 & 0 & 1 & -1 & 2,1 \\
8 & 0 & -1 & 1 & 4,79 \\
9 & 1 & 0 & 1 & 5,1 \\
10 & -1 & 0 & -1 & 1,63 \\
11 & 1 & 0 & -1 & 2,55 \\
12 & -1 & 0 & 1 & 4,25 \\
13 & 0 & 0 & 0 & 3,41 \\
14 & 1 & 1 & 1 & 5,1 \\
15 & -1 & -1 & -1 & 1,63 \\
16 & -1 & 1 & 1 & 4,28 \\
17 & -1 & -1 & 1 & 4,25 \\
18 & -1 & 1 & -1 & 1,63 \\
19 & 1 & -1 & -1 & 2,58 \\
20 & 1 & -1 & 1 & 5,1 \\
21 & 1 & 1 & -1 & 2,58 \\
22 & 0 & 0 & -1 & 2,15 \\
23 & 0 & 0 & 1 & 4,67 \\
24 & 0 & 1 & 0 & 3,41 \\
25 & 0 & -1 & 0 & 3,41 \\
26 & 1 & 0 & 0 & 3,9 \\
27 & -1 & 0 & 0 & 2,97 \\
\hline
\end{tabular}

У результаті обробки експериментальних даних одержали математичну модель другого порядку для визначення вихідної напруги тензодатчиків яка наведена у кодованому вигляді:

$$
y=3,40185+0,4489 x_{1}+0,00333 x_{2}+1,292222 x_{3}-0,033292 x_{1}^{2}-0,026625 x_{2}^{2}-
$$

$$
-0,03163 x_{3}^{2}+0,001667 x_{1} x_{2}-0,45 x_{1} x_{3}-0,0075 x_{2} x_{3}-0,00375 x_{1} x_{2} x_{3} .
$$

Проводили розкодування кодованих значень коефіцієнтів рівняння регресії відповідно до програми обробки результатів планованих експериментів в оболонці редактора Excel.

3 розкодованими значеннями коефіцієнтів рівняння регресії математична модель вихідної напруги тензодатчиків набуде натурального вигляду:

$U=3,885238679-65,23870982 S+4,564634217 L+20,11022336 M-53,2672 \cdot S^{2}-16,640625 L^{2}+$

$+1,915547548 M^{2}+1,667 S \cdot L-140,07782 \mathrm{I} \cdot M+1,45914396 \mathbb{L} \cdot M$,

За результатами експерименту побудовано графічну залежність (рис. 3) зміни вихідної напруги $U$ сенсора крутного моменту від зміни зусилля крутного моменту $M$ приводу обертових елементів.

3 графічної залежності (див. рис. 3) видно, що зміна вихідної напруги $U$ сенсора крутного моменту від зміни зусилля крутного моменту $M$ при різних конструктивних розмірах вимірювальної площини зростає прямолінійно. Максимальна вихідна напруга сенсора $U$ досягається при величині крутного моменту $M=0,42 \mathrm{H} \cdot \mathrm{M}$, ширині тензовимірювальної площини 35 мм, довжині 165 мм та товщині 2,5 мм становить $U=5,1 \mathrm{~B}$.

Дані досліджень були перевірені на відтворення. Для цього визначали розрахункове значення критерію Кохрена $G_{\text {роз }}$ за методикою [6]. Число степенів вільності чисельника і знаменника становить: $f_{u}=3-1=2, f_{3}=27$. Дане значення критерію $\epsilon$ менше від 
табличного $G_{p o s}=0,17$ яке становить $\left[G_{\text {таб }}\right]=0,1980$, що підтверджує відтворюваність досліду.

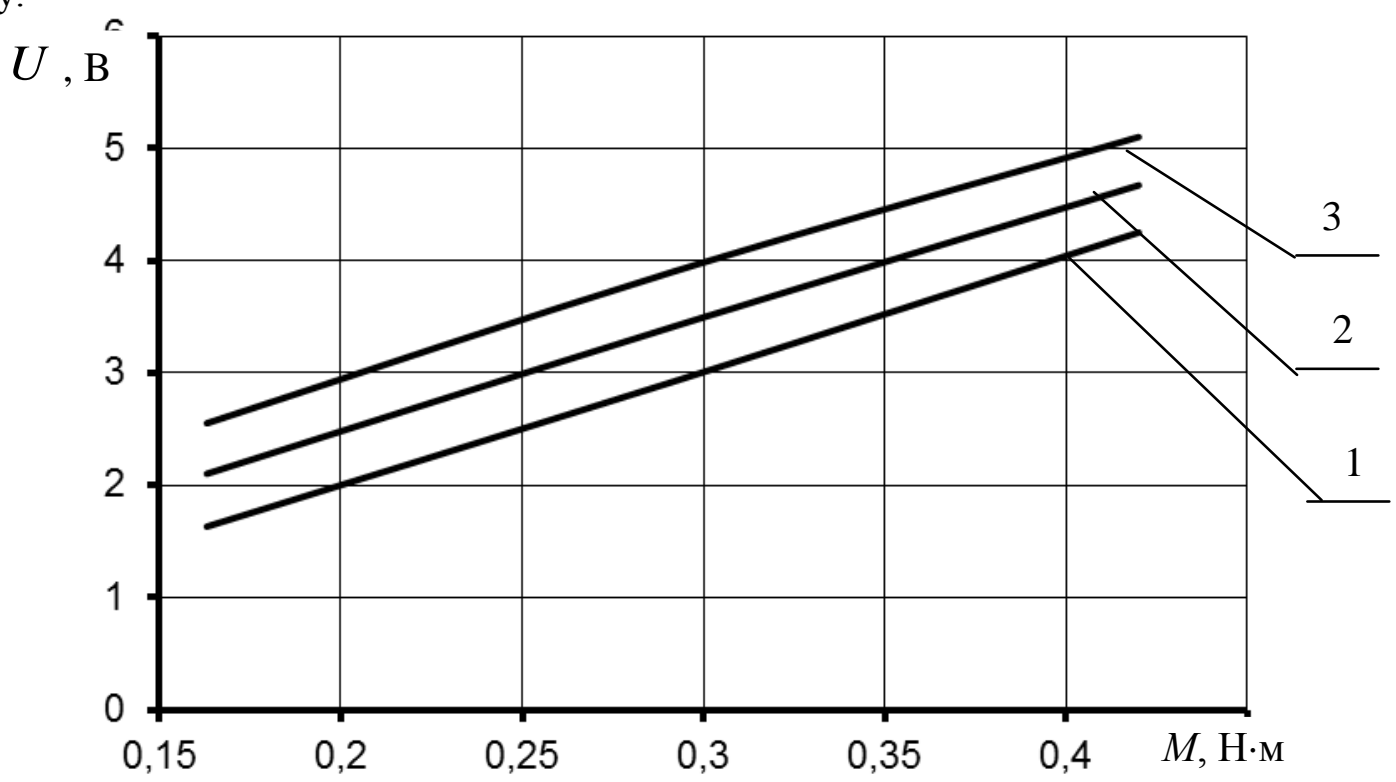

Рис. 3. Графік залежності зміни вихідної напруги $U$ сенсора крутного моменту від зміни зусилля крутного моменту $M$ елементів, що обертаються:

1- при ширині тензовимірювальної площини 25 мм, довжині 85 мм та товщині 1,5 мм; 2- при ширині тензовимірювальної площини 30 мм, довжині 125 мм та товщині 2 мм; 3- при ширині тензовимірювальної площини 35 мм, довжині 165 мм та товщині 2,5 мм.

Перевірку досліджень проводили за критерієм Фішера $F_{\text {роз }}$ за степенем вільності чисельника $f_{u}=7$ знаменника $f_{3}=63$ становить $F_{p o з}=2,0$. Умова адекватності виконується, оскільки $F_{\text {роз }}\left\langle\left[F_{\text {таб }}\right]=2,3\right.$.

Висновки. Для дослідження потужності приводу обертових елементів була розроблена конструкція сенсора крутного моменту для проведення експериментальних досліджень.

У результаті проведення планованого багатофакторного експерименту одержано рівняння регресії для визначення вихідної напруги $U$ сенсора крутного моменту від зміни зусилля крутного моменту $M$ приводу обертових елементів. Аналіз математичної моделі дозволив встановити, що зміна вихідної напруги $U$ сенсора крутного моменту від зміни зусилля крутного моменту $M$ при різних конструктивних розмірах вимірювальної площини зростає прямолінійно. Максимальна вихідна напруга сенсора $U$ досягається при величині крутного моменту $M=0,42 \mathrm{H} \cdot$ м, ширині вимірювальної площини 35 мм, довжині 165 мм та товщині 2,5 мм становить $U=5,1$ В. Мінімальна вихідна напруга датчика $U$ досягається при величині крутного моменту $M=0,163 \mathrm{H} \cdot$ м, ширині вимірювальної площини 25 мм, довжині 85 мм та товщині 1,5 мм становить $U=1,63 \mathrm{~B}$.

\section{Інформаційні джерела:}

1. Шушкевич В.А. Основы электротензометрии. Минск: Вышэйш. шк., 1975. 351 с.

2. Полищук Е.С. Электрические измерения электрических и неэлектрических величин Москва: Энергия, 1980. 360 с.

3. Якимчук Д. М., Кармаліта А. К. Аналіз методів вимірювання крутних моментів в приводах електрогідравлічних пресів легкої промисловості. URL: http: //ekhsuir.kspu.edu/handle/123456789/2878 (дата звернення 19.11.2020).

4. Васілевський О.М. Засіб вимірювання динамічного моменту електромоторів та аналіз його точності . Вимірювальна техніка та метрологія. № 73. 2012. - С. 52 - 56.

5. Вимірювач крутного моменту: патент 70691. Україна, MКИ G01L5/00, G01L5/24. 2. № 200312121556 ; заявл. 23.12.2003; опубл. 15. 10.2004, Бюл. №10. 4 с.

6.Мельников С. В., Алешкин В. Р., Рощин П. М. Планирование эксперимента в исследованиях сельскохозяйственных процессов. Ленинград: Колос, 1980. 163 с. 
7. Львович Я. Е., Фролов В. Н. Теоретические основы конструирования, технологии и надежности РЭА. Москва: Радио и связь, 1986. 192 с.

8. Бондар А.Г. , Статюха Г.А., Потяженко И. А. Планирование эксперимента при оптимизации процессов химической технологии. Київ. Вища школа, 1980. 261 с.

Банга В.И., к.Т.н.

Львовский национальный аграрный университет

\section{ЭКСПЕРИМЕНТАЛЬНЫЕ ИССЛЕДОВАНИЯ СЕНСОРА КРУТЯЩЕГО МОМЕНТА СИСТЕМЫ ПРИВОДА «ЭЛЕКТРОДВИГАТЕЛЬ-ДИСКОВЫЙ ДОЗАТОР»}

В статье представлен обзор и анализ устройств для измерения крутямего момента привода вращающихся элементов, конструктивную схему и общий вид сенсора крутящего момента,предусмотрено наличие средств для измерения, регистрации и передачи информации электрическими сигналами бегущих значений выходного напряжения тензодатчиков в динамическом режиме, отображение и хранение информации и контрольно-измерительные приборы.

Приведена блок схему, общий вид экспериментальной установки для исследования мощности привода «электродвигатель-дисковый дозатор» сенсором крутящего момента, результаты экспериментальных исследований с использованием теории многофакторного планируемого эксперимента, представлены уровни варьирования факторов, матрииу плана эксперимента.

Предложенная конструкиия сенсора крутящего момента системь привода «электродвигатель-дисковый дозатор позволит упростить снятие информации с сенсора при его вращении, повысить точность измерения и передачи измерительного сигнала $\kappa$ компьютеру, упростить его изготовление.

В результате проведения планируемого многофакторного эксперимента получень уравнения регрессии для определения выходного напряжения сенсора крутящего момента от изменения усилия крутящего момента вращающихся элементов при различных конструктивных размерах тензоизмерительной плоскости.

Ключевые слова: сенсор крутящего момента, дисковый дозатор, экспериментальная установка, планируемый эксперимент, выходное напряжение, тензодатчик.

\section{Banha V.I., Ph.D.}

Lviv National Agrarian University

\section{EXPERIMENTAL STUDIES OF THE TORQUE SENSOR OF THE DRIVE SYSTEM «ELECTRIC MOTOR-DISC DISPENSER»}

The article presents an overview and analysis of devices for measuring the torque of the drive of the rotating elements, the structural diagram and a General view of the torque sensor, provides for the availability of means for measuring, recording and transmitting information by electrical signals of the current values of the output voltage of strain gauges in dynamic mode, display and storage of information and control and measuring devices.

The block diagram, general view of the experimental setup for studying the power of the drive "motor-disk dispenser" torque sensor, the results of experimental studies using the theory of multifactor planned experiment, the levels of variation of factors, the matrix of the experimental plan.

The proposed design of the torque sensor of the drive system "motor-disk dispenser will simplify the removal of information from the sensor during its rotation, increase the accuracy of measurement and transmission of the measuring signal to the computer, simplify its manufacture.

As a result of the planned multifactor experiment, a regression equation was obtained to determine the output voltage of the torque sensor from the change in the torque force of the rotating elements at different structural dimensions of the strain gauge plane.

Keywords: torque sensor, disk dispenser, experimental setup, planned experiment, output voltage, strain gauge. 